Article

\title{
Digital Survey for the Archaeological Analysis and the Enhancement of Gropina Archaeological Site
}

\author{
Stefano Bertocci ${ }^{1, *,+}$, Andrea Arrighetti ${ }^{2, *,+}$ and Matteo Bigongiari ${ }^{1, *,+}$ (D) \\ 1 Department of Architecture, University of Florence, 50121 Florence, Italy \\ 2 Department of Historical Sciences and Cultural Heritage, University of Siena, 53100 Siena, Italy \\ * Correspondence: stefano.bertocci@unifi.it (S.B.); andrea.arrighetti@unisi.it (A.A.); \\ matteo.bigongiari@unifi.it (M.B.) \\ + These authors contributed equally to this work.
}

Received: 24 January 2019; Accepted: 28 February 2019; Published: 13 March 2019

\begin{abstract}
This paper concerns the path of knowledge that leads to the understanding of the morphology and evolution of the archaeological area discovered in the 1960s below the parish church of Gropina (AR). By dealing with archaeological surveying methods, the attention is focused on the digital survey technologies used, integrating data from laser scanner instruments with photogrammetric ones. The morphological base was necessary for the preparation of stratigraphic analyses, and allowed us to check the previous studies carried out on the building to extract a periodized planimetry. Finally, the digital drawing technologies have allowed us to hypothesize the schematic evolutionary models of the different phases of the building, and to use the digital survey to create a virtual platform through which to interact with the archaeological site, which is now closed to visitors.
\end{abstract}

Keywords: digital survey; archaeology; Gropina

\section{Introduction}

The era of digitization has greatly influenced the fields of architecture and relief, leading to an increase in detection methodologies over the past 20 years, through the tools and software that have led to the use of digital capture, such as laser scanners and photomodeling [1,2].

The theme of the digital survey aimed at the documentation and analysis of archaeological sites has been a subject for the DiDA (Architecture Department) Survey Laboratory of the University of Florence for many years [3]. This research area includes the documentation project of the Gropina's parish church, which began in April 2016 and involved students and researchers of the DiDA survey course (Figure 1).

Gropina's parish church is located in the municipality of Loro Ciuffenna, in the Upper Valdarno, in an area that has been settled since the Lower Palaeolithic period. During the Etruscan period, large settlement systems did not develop, but in the hilly areas there were small villages (the toponym Gropina could come from the Etruscan language, krupina meaning village); on the hills above Gropina, in the 1950s, a series of tunnels from the Etruscan period was found by the superintendence, attesting their presence in the area [4].

In Roman times, following the construction of the Via Cassia Vetus, corresponding to the current via dei Setteponti [5], the whole area enjoyed a flourishing commercial period that testifies to the birth of many settlements. The walls that were found during the archaeological excavations below the parish church are probably the remains of a residential building belonging to this period. 


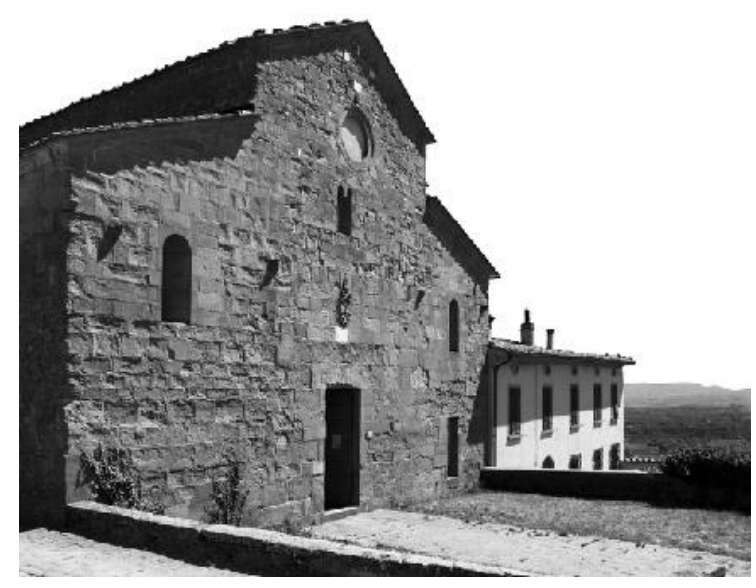

(a)

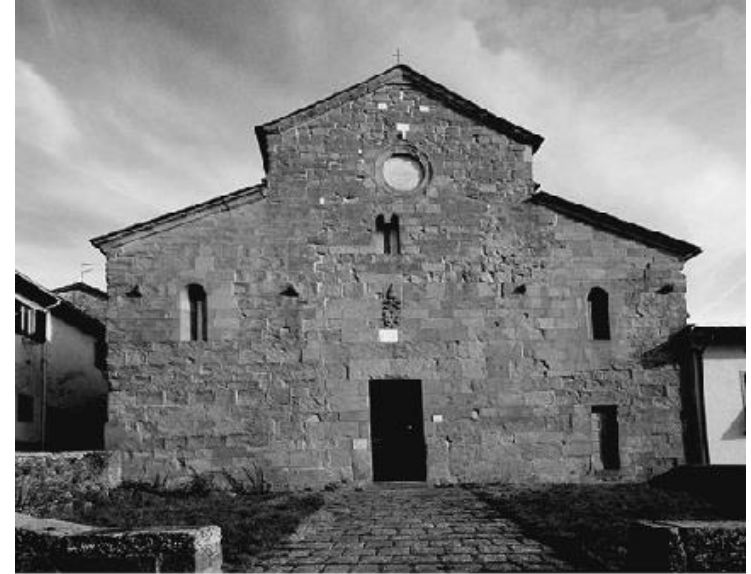

(b)

Figure 1. (a,b) View of Gropina's parish church facade.

This research project, carried out by the University of Florence, aims to document the main features of the building. Firstly, a three-dimensional database was created from which to extract the morphological information necessary to set up the subsequent thematic analysis.

The realization of a three-dimensional survey (Figure 2) also has the purpose of studying and documenting the archaeological excavations conducted by the superintendency, in order to broaden the knowledge obtained and to allow us to better understand and analyze the traces of the past. In this process, the "drawing" - the tool used to reach a synthesis of data collected in the field-is fundamental support for the transmission of information among the different operators who contribute to the study of the monument. On the basis of what has been drawn, the archaeologist sets his own considerations regarding the building stratigraphy and construction phases.

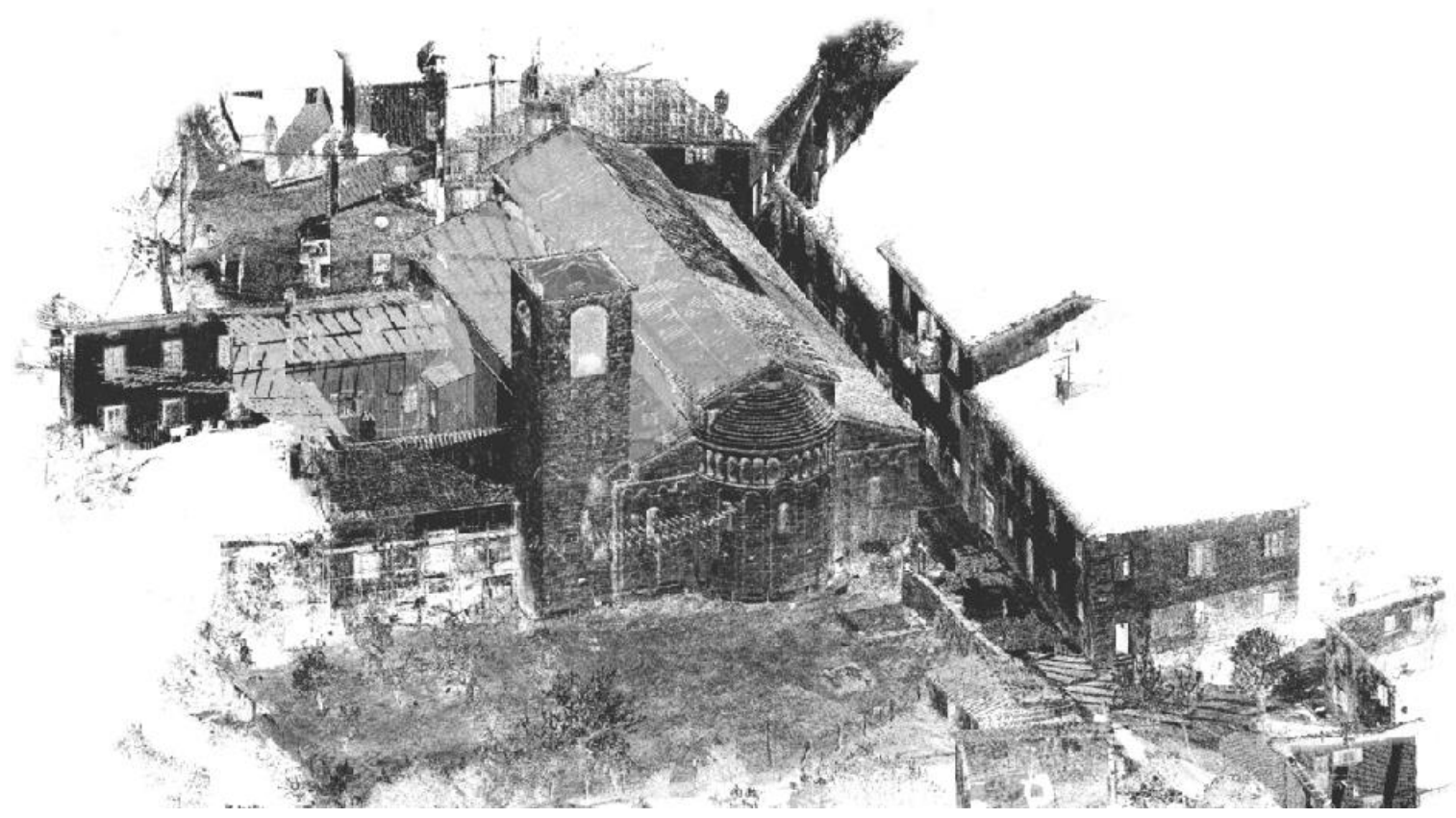

Figure 2. Axonometric projection of the registered point cloud of the church, which shows how it is inserted in the surrounding village.

Analyzing and interpreting the historical-archaeological data in excavation areas already investigated in the past is a process that considerably limits the knowledge of the object. The 
conclusions regarding the walls are based, in fact, only on the structures left visible today in situ during the previous excavation, and refer to the last layer investigated (the oldest). The history of the building is inevitably destroyed after the excavation operations. Archaeological interpretations are often included in more or less precise documentation that helps in the interpretive process of some historical periods, often the most ancient, but they are incomplete for the most recent chronological periods. It also has to be considered that the excavation, interpretation, and analysis methods of an archaeological site have changed and have been considerably refined over the last years. It is therefore essential to propose an archaeological analysis of the visible architectures of a building, integrating the data of the past with the new digital detection methods. This operation deepens the documentation of excavations, which were typically made 30 or 40 years ago, to complete the knowledge of the building, which is indispensable in terms of the research but even more so for the restoration and enhancement of the building.

\section{Materials and Methods}

This documentation project of the parish church of Gropina and its archaeological finds started with a first phase of historical research in the archives of the superintendence of Arezzo. Within the archive are collected drawings and reports of interventions that, since the discovery of the masonry below the pavement of the current parish church, have led to the excavation operations and subsequent musealization of the ancient finds.

The archive of drawings also describes, in a clear and unmistakable way, the relationships between the rediscovered masonry, as interpreted by the archaeologists at the time of excavation. It is necessary to highlight how complex it is to analyze archaeological finds already found many years ago (already morphologically discretized and partly attributed to a defined time period); it is, therefore, important, in order to further contribute knowledge to the history and architecture of the site, to analyze in depth the morphology of the object of study.

The survey applied to archaeological areas must pay attention to all those characteristics of the architectural object that can provide important information to the figure of the archaeologist, in order to conduct his analysis (Figure 3). It becomes necessary to describe the walls in a scale of detail useful for the definition of different wall sections, the stone-working process, and the relationships between masonry or adjacent architectural elements. To be able to define these characteristics, the morphological survey must be completed by detailed photographic information. The photographic data facilitate the process of the stratigraphic units' detection, especially during the graphics rendering of the analysis; in fact, photography is the expression of a more objective fact compared to the wireframe drawing of the stones, which clearly depends on the drawer's subjective interpretation.

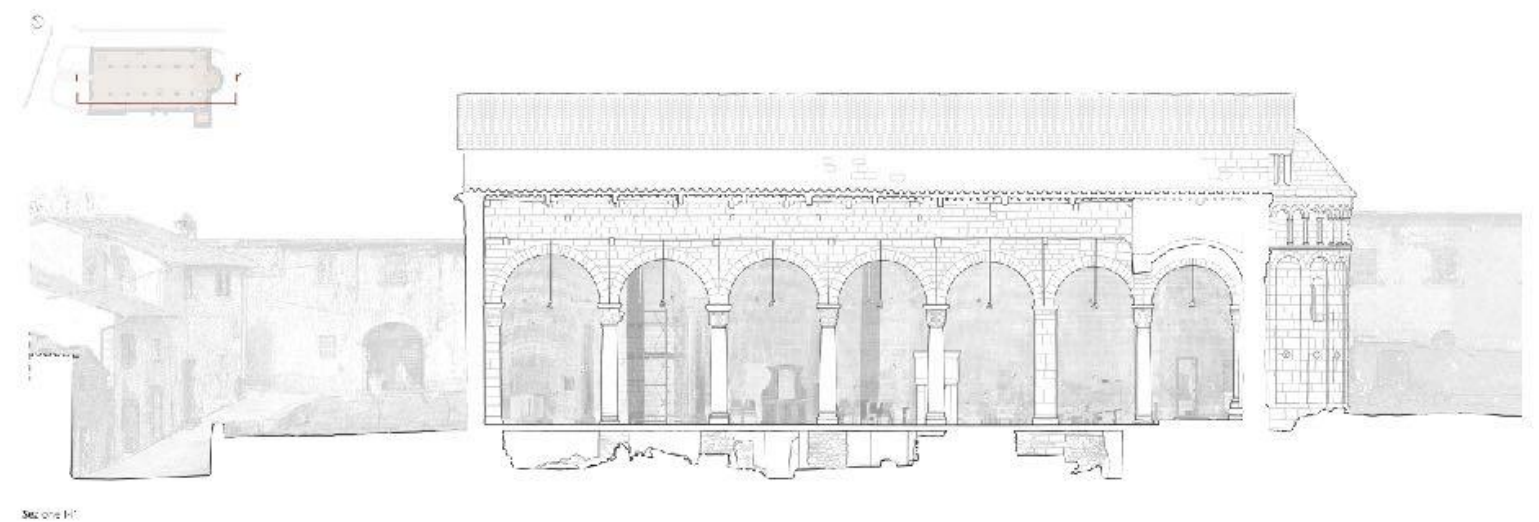

Figure 3. Two-dimensional wireframe transversal section of an aisle of the church, where it is possible to see how the existing medieval church is based on the older walls. 
A survey phase was planned that involved the entire building and described how it was inserted in the surrounding village. The surveying operations were performed using digital methodologies, integrating data from laser scanner instruments and photographic data obtained through SfM acquisitions.

Firstly, a laser scanner survey was planned. Before starting with the operations, some considerations about the church and its surrounding morphology were made. Considering the dimension of the church and the complexity that is faced when the survey of narrow spaces such as the bell tower and the underground archaeological churches has to be made, it was decided that a Faro Focus 3D scanner would be used, which guarantees lightweight, dense, and fast cloud acquisition, even though it performs less precise measurements (in the order of the millimeter). During the design phase of the survey, we decided to create a point cloud that described the surfaces of the architecture with at least one point for each centimeter; the high density of information was really important for this church in order to give the archaeologist an instrument of investigation which could report plenty of information.

After registering about 100 laser-scanner workstations, a general point cloud of the entire area was obtained. The registration of point clouds has been done in different ways, and those possibilities allowed by the software (which are useful for the point cloud management and registration) have improved following the development of laser scanner instruments over the years. The first instruments needed quite a long time to create a full $360^{\circ}$ scan with a high point density-more than $30 \mathrm{~min}$. As a result of this, when an architect had to design a survey of a building, they usually could not set many scan positions, but only a few were needed to recreate the general morphology of the building.

In order to obtain a reliable registration, it was useful to insert some targets in the scan scene (such as spheres or black and white checkers) and to measure them with a total station, to contain the eventual registration error on the targets. The arrival of fast instruments that could measure up to 1 million points/sec offered the possibility of obtaining a really dense 3D model of a building in a short time, in the same way it was possible to have a high overlapping parts between two scans-the software evolved, giving the chance to register the scan positions and compare the morphology of two contiguous scans. In the registration phase, the alignment was obtained by overlapping clouds, rather than using black and white targets; this way, the acquisition phase of the data was greatly accelerated, especially in those parts that are difficult to access, such as the underground parts due to the poor height of the compartment. The possibility of scanning around the whole building allowed us to create a traverse composed of the scan locations, which was really important in order to evaluate the error made during the registration phase [6]. This way, considering the small dimension of the building, it was not necessary to have the support of a total station, and we could use the GPS integrated with the scanner to obtain the geographic reference. The final registration error was lower than the one accepted by the 1:50 return scale [7]. The misalignment was not evaluated on the parameters provided by the software but by checking the errors with certification procedures which analyze the misalignment on the cloud section [8].

Regarding the photographic survey, we decided to realize many parts of the architecture, creating different SfM models, in order to obtain mesh and texture models with a better resolution. The photographic models (realized with the software Photoscan Pro v.1.2.0) were referenced and scaled on the basis of coordinates of homologous points with the point cloud of the laser scanner. The acquisition phase of the archaeological parts of the complex necessitated paying particular attention to the use of diffused surface-lighting systems, which eliminated the shadows provided by the lighting fixtures present. This was possible through the use of spotlights, which helped to eliminate the problems of illumination and shadows that come from the small Romanic windows of the church and the old lighting system. It was also important to recreate 3D models and colors of truly reliable textures. The color calibration was possible using a color checker, which was positioned in each frame and allowed us to calibrate the color of the photos on the computer. 
Two-dimensional drawings were made from the point cloud to describe the medieval building and the archaeological remains in the subsoil. The detection of the archaeological area was complex due to the impossibility of moving freely with the laser instrument because of the height of the ceiling - which did not always permit us to reach every zone easily —and due to the lack of adequate light illumination that is necessary to allow the operator to gather a correct photographic acquisition. The plan and the vertical sections describe the complexity of the archaeological site both in its morphology and in the composition of the single masonry (Figure 4). The three-dimensional database allowed us to visualize and draw useful information for the definition of the stratigraphic units at different scales, depending on the needs, dimensions, and different processing of the stone blocks.

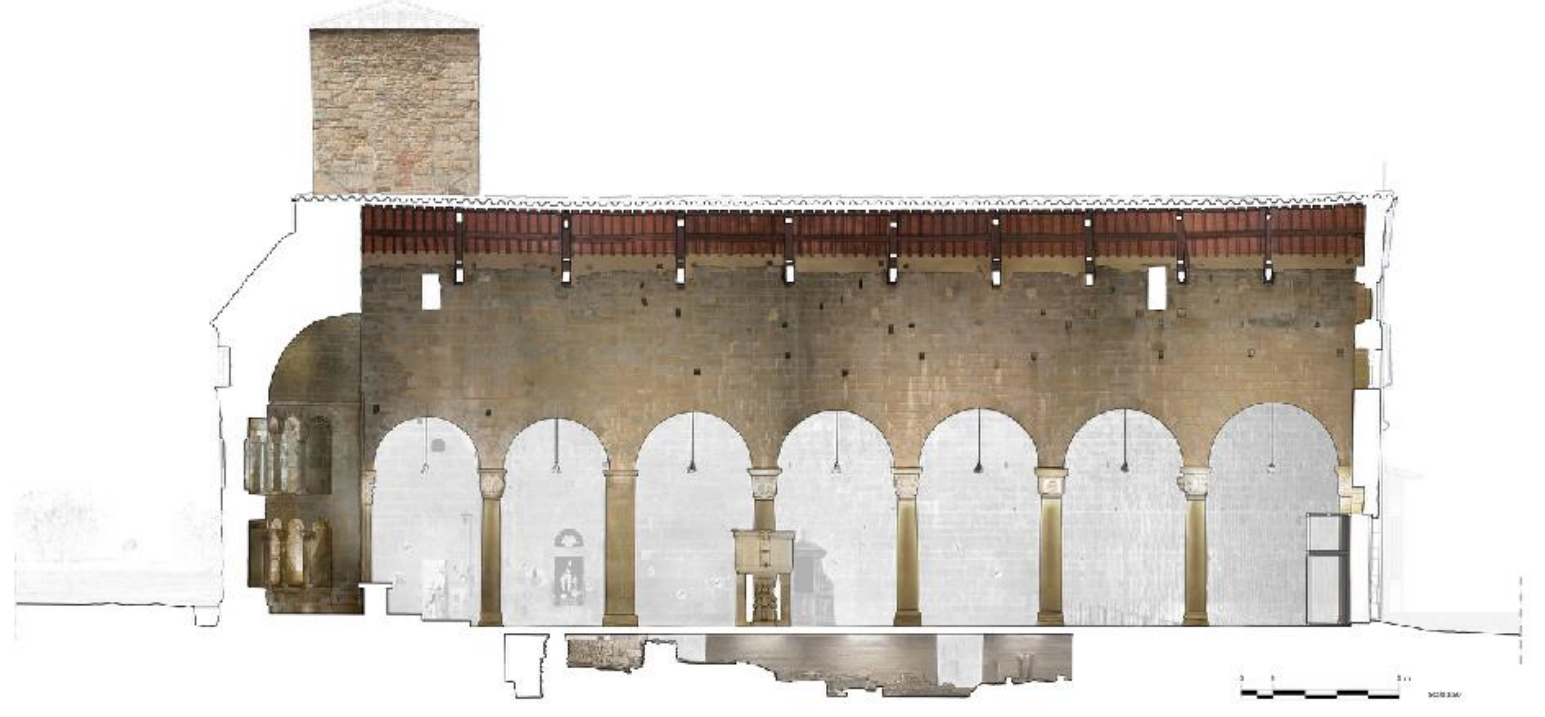

Figure 4. Two-dimensional main transversal section of the church, mapped with the orthophoto that shows the position of the ancient structures, and the modern concrete walls designed to let people visit the lower level.

The two-dimensional drawings of the underground area have been integrated with the three-dimensional one, whose purpose is completely different from the "classic" drawings in plan and section. Specifically, the orthogonal projection drawing is a technical design as it is intended for the transmission of information between the various operators within a project (in this case the architect-surveyor and the archaeologist). Meanwhile, the three-dimensional representation is easier to understand and is ideal for transmitting knowledge to non-technicians. In the hypothesis of the realization of a museum tour that allows visitors to get in touch with the underground finds, different fruition systems can be envisaged.

A traditional solution is the construction of a three-dimensional scale model that describes the archaeological area; it allows the visitor to understand the morphology of the spaces under the floor of the current parish church and their location in reference to the current building. The real maquette also allows visually impaired people to come in contact with the surfaces of objects, and to imagine a three-dimensional development of the building, which is not possible with the digital medium. A more modern solution is the creation of a virtual platform that allows the visitor to come in contact with the architecture, using a viewer or a touch screen, in order to navigate and investigate the most significant parts. In both cases it is necessary to realize a digital three-dimensional model first-in the case of the real model, the model needs to be printed in 3D, and in the case of the three-dimensional platform, the navigable model must also be inserted [9]. This three-dimensional object was created starting from the laser scanner point cloud-the file was exported in a reverse engineering software (Geomagic Design X) where it was possible to triangulate the points of the cloud in order to obtain 
a scaled mesh surface (the mesh detail cannot go beyond that of the point cloud). The mesh was optimized, and it was possible to map it with the textures coming from the photogrammetric models.

For the three-dimensional representation of the site, two different methodologies were used-modeling based on reality-based acquisitions, and models that reproduce the real object with reliability to the centimeter. Furthermore, in order to understand the spaces and transmit information, modeling was also implemented through software (Rhinoceros) that manage NURBS (non uniform rational basis-splines) surfaces. In this case, we did not take care of the millimetric correspondence of the surfaces with the real ones. The morphological data were synthesized to a reduced definition scale recreating the geometry of the archaeological area. This type of representation has been useful to realize simplified evolutionary schemes that allow the immediate understanding of the building and shows the changes (interpreting the data coming from the archaeological analysis) that the site has faced over time.

The drawings obtained from the digital survey formed the database, together with the point cloud and the photos used by the archaeologists to investigate the church and the excavations. The reliability of the drawings and the possibility of analyzing the church using a navigable 3D model, helped the archaeological analysis to have correct morphological data where to insert the thematic maps.

\section{Results and Discussion}

The area in the subsoil of Gropina's parish church is characterized by a series of architectural complexes of different historical periods (Figure 5). They were found after archaeological excavations carried out in the 1960s and 1970s by the superintendence when they rebuilt the floor of the building to eliminate a strong presence of humidity (Figure 6). The results that emerged from the excavations confirmed what was already reported in the bibliographical references-they attest to the presence, in the same place, of a religious building dated to the VIII century AD on the basis of sepulchral slabs [10]. The archaeological survey also allowed us to produce innovative data on the history of the area, highlighting two other complexes prior to the eighth century church-few traces remain of the apsidal structure, interpreted as a seventh-century paleochristian "ecclesia", and, before this, a masonry building defined by archaeologists as a Roman settlement [11].

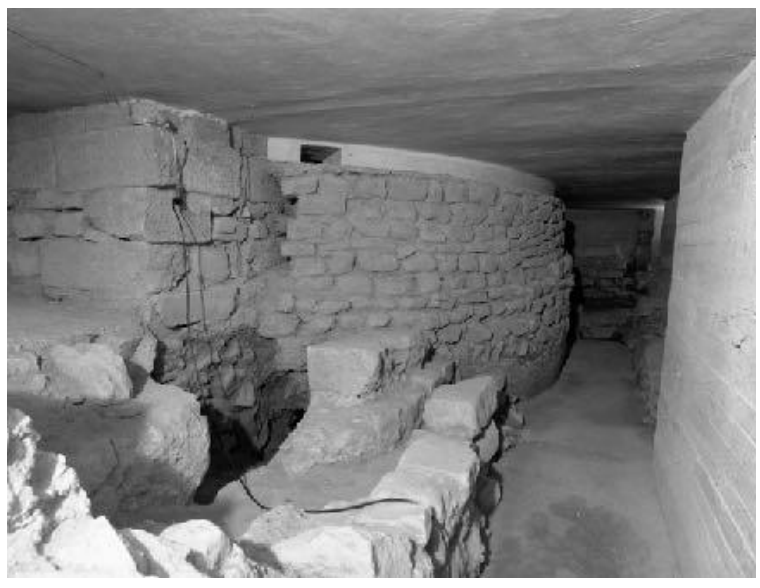

(a)

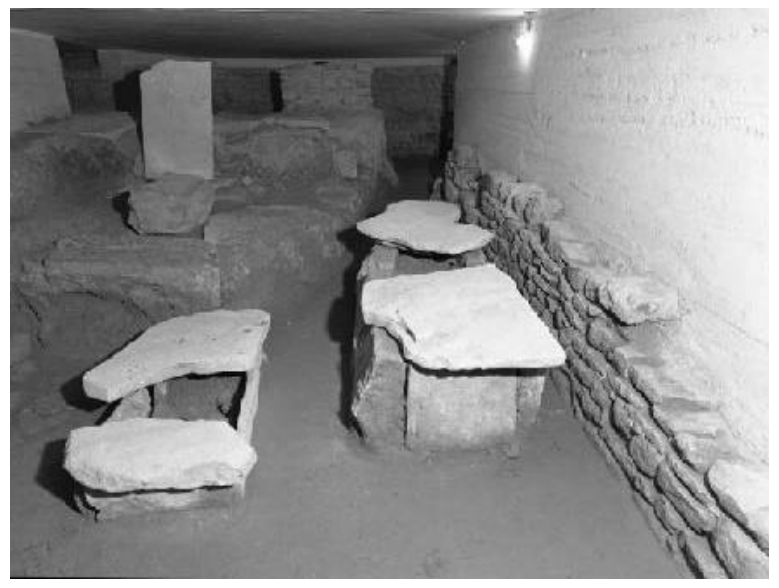

(b)

Figure 5. (a) Picture of the ancient Longobardic apse of the church; (b) picture of Longobardic tombs and other archaeological remains from the superintendence archives.

On the occasion of the survey carried out in 2016, a new stratigraphic analysis was carried out on the masonry of the structures described above, using the methodologies of the Archaeology of Architecture [12-14]. The analysis confirmed the findings of the excavation reports, attesting the presence of at least three buildings (CF) preceding the current Romanesque church. 


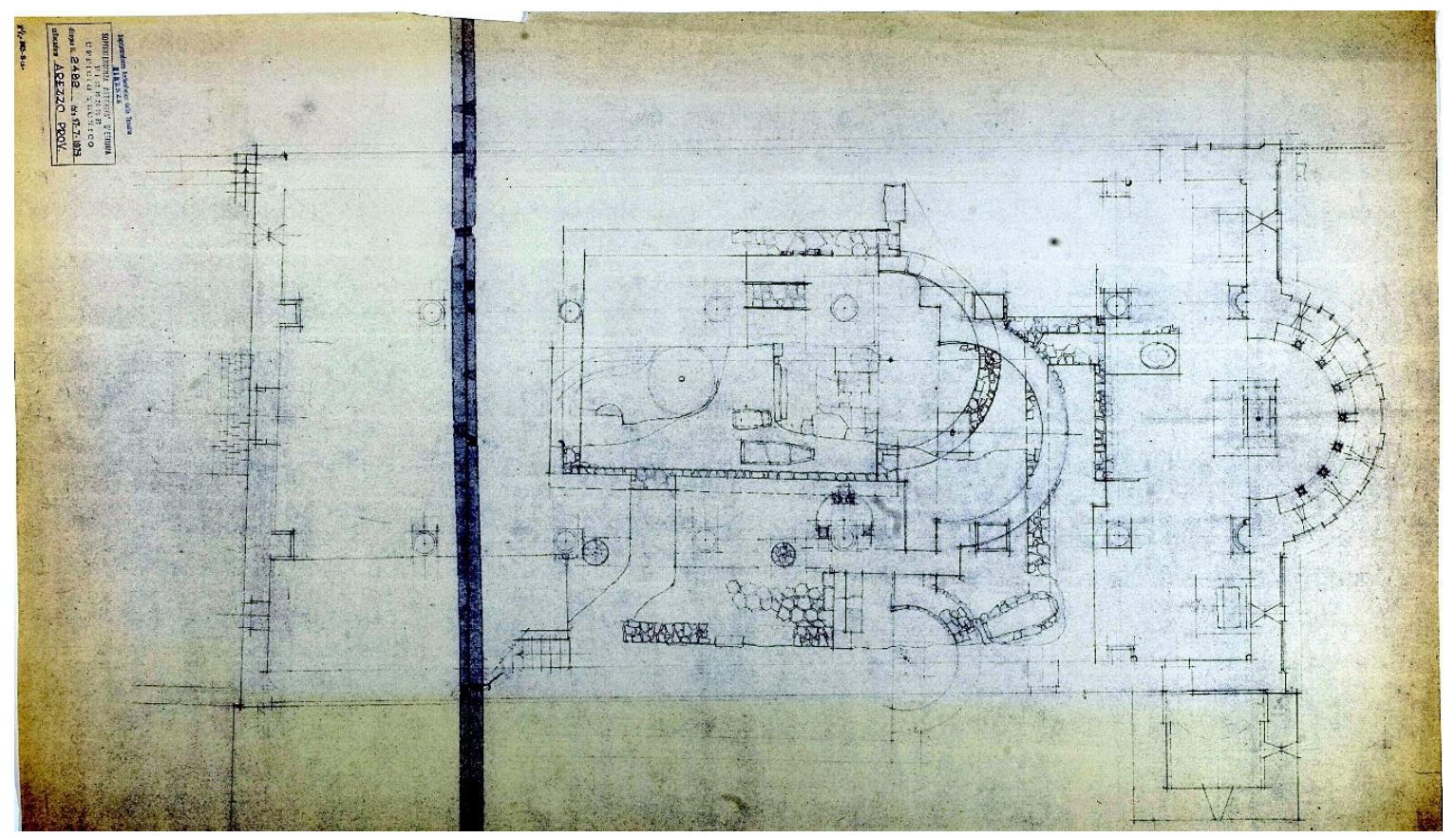

Figure 6. Plan of the ancient churches after the archaeological excavation. Arezzo archaeological superintendence (1973).

For issues of space and focus, the first chronologically identified structure, probably from the Roman era, was not specifically discussed; the analysis focused on the second structure, built directly on the walls of the classical era and of clear religious vocation. The currently visible part, of which unfortunately only a few portions of masonry remain, seems to refer to a single-nave church. The materials found following the archaeological excavation directed by Maetzke allowed us to attribute the building to the early Christian period [15], of which there remain two portions of the apse-a perimeter wall and a small part of the pavement. Stratigraphically, the building was built in a period following the structure of the Roman period (it exploits its walls as foundations) but precedes an additional religious building, built above it, whose portion cuts the apse of the early Christian building. It is currently difficult to establish a more specific dating for this structure because there is no comparison material available for a chrono-typology of the identified masonries or specific chronological indicators, and there is no possibility of conducting laboratory analysis on construction materials.

On the second building, there is a third structure with characteristics belonging to a place of worship (there are aisles, apse, colonnade, and internal burials) built up and transformed into two construction periods-a church with a single apsed hall and an extension of the building with the construction of a second apsidal nave on the south side. Regarding the first constructive period, today only the apse is visible, which is cut to the south-east by the foundation of a Romanesque pillar. It is made with "un'ossatura muraria semicircolare in filaretto rustico di pietra appena sbrecciata ed unita con calce aderentissima" [16].

It is also possible to identify small portions of perimeter walls connected to the apse to the south-east and north-west. Regarding the second construction phase, a portion of the apse that ends the side aisle and a part of the masonry that stratigraphically leans on the wall of the early church is visible and is therefore chronologically subsequent to it.

In this phase, the construction of at least two columns is attested (the only two currently preserved) which divide the central nave from the lateral aisle. Between these two constructive periods, there seems to be a moment, which is difficult to interpret, when there was a foundation of a central wall at the aisle; this was stratigraphically in phase with some stone slabs forming a paved area with three steps. These steps cover the aforementioned wall, whose height is closely related to the first and second 
phase church. Since the pillars are built in the second phase, they are therefore cut into the pavement; the pavement seems to belong to the first construction phase, even if it is placed topographically outside the perimeter wall of the mono-apsed church. It is therefore very complex to define a specific function for this element. Another element that cannot currently be evaluated is the northern portion of the religious building of the eighth century, where the construction of the current parish church and its subsequent modifications have canceled the pre-existence of this structure (in this area there are only some wall structures related to the Roman building).

In conclusion, the construction of the Romanesque parish precedes the building of two other religious buildings. They had a significantly lower floor space; the first one was a single-nave church, probably from the early Christian period dating back to the seventh century, and the second one, from the eighth century, was also initially a single-nave church and was later enlarged with the construction of at least one nave on the south side (Figure 7; Figure 8).

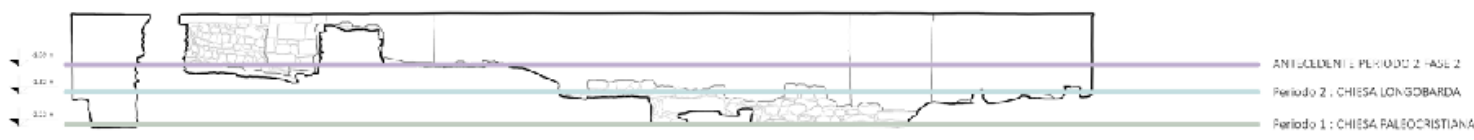

Figure 7. Section of the main nave of the site; green: first period (VII century); purple: second period, first phase (VIII century); cyan: second period, probably between first and second phase.

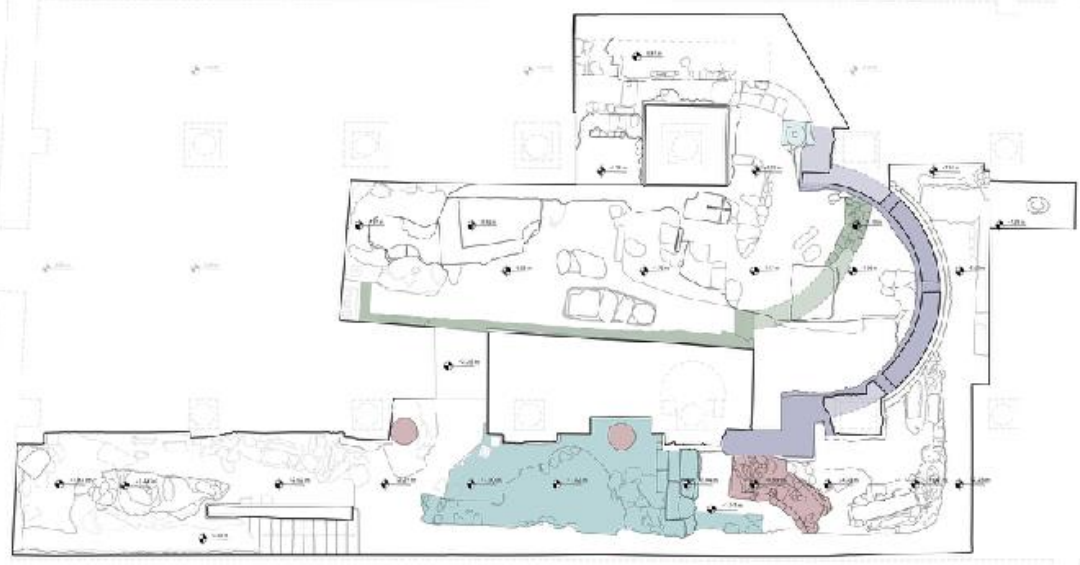

Figure 8. Plan of the archaeological site; green: first period (VII century); purple: second period, first phase (VIII century); red: second period, second phase (post VIII century-ant XI century); cyan: second period, probably between first and second phase.

\section{Conclusions}

The results obtained from the survey and the archaeological analyses were summarized in a periodized plan that correlates the masonry walls present in the archaeological site to the construction phases of the different buildings that have been replaced over time on the Gropina's site. This information supplements and updates the excavation reports conducted in previous years. Further development of the research consists of the archaeological analysis of the medieval building-by combining the stratigraphic considerations with the diagnostic and structural analysis of the building, the static-dynamic behavior can be understood so as to plan effective consolidation operations if they are necessary.

The digital survey is a fundamental tool for the study and the development of considerations on the evolution of archaeological sites. Nevertheless, the need to establish regulations and procedures aimed at the documentation of the excavation area is clear, in order to create a fundamental document 
for the analysis of the stratigraphic relations between the various phases of construction of a building; these are otherwise difficult to identify, as in the case of the church object of this study.

Author Contributions: S.B. is the author of Section 1 (Introduction); M.B. is the author of Section 2 (Material and Methods); A.A. is the author of Section 3 (Results and Discusion).

Funding: This research received no external funding.

Acknowledgments: The research project concerning the documentation and analysis of Gropina Parish Church was possible thanks to the collaboration between the Survey Lab. of DiDA (department of architecture), Florence University, the LAArch (Archaeology of building Lab.) of DSSBC (Historical sciences and cultural heritage department), Siena University and the municipality of Loro Ciuffenna (AR). The drawings are the result of a year of research conducted in the Architectural Survey Course (ay 2015-2016), coordinated by the writers and concluded with a master's thesis in architecture (Elisa Parrini, discussed in April 2017) which analyzes how to use digital survey for the documentation on ancient buildings.

Conflicts of Interest: The authors declare no conflict of interest.

\section{References}

1. Rinaudo, F. La tecnica laser scanning:applicazioni architettoniche e urbanistiche. In La tecnica del laser scanning: teoria e applicazioni; a cura di Fabio Crosilla e Riccardo Galetto; CISM: Udine, Italy, 2003.

2. De Luca, L. La fotomodellazione architettonica; Di Flaccovio editore: Palermo, Italy, 2011.

3. Bertocci, S. Digital technologies for documentation of archeological sites; three project for Villa Adriana in Tivoli (Rome), the Fortress of Masada (Israel) and the Basilica of the Nativity in Bethlehem. In Dibujo $y$ arquitectura; Chias, P., Cardonemm, V., Eds.; Universidad de Alcalà: Alcalá de Henares, Spain, 2016.

4. Archivio della Soprintendenza alle Antichità d'Etruria (anni 1950-1961) Oggetto: Loro Ciuffenna-loc. Gropina. Firenze.

5. Vilucchi, S. Nuovi dati sul percorso della 'via dei Setteponti'. In Fortuna e declino di una società feudale valdarnese. Il Poggio della Regina; Vannini, G., Ed.; Società Editrice Fiorentina: Firenze, Italy, 2002.

6. Bertocci, S.; Minutoli, G.; Pancani, G. Rilievo tridimensionale e analisi dei dissesti della Pieve di Romena. Disegnare con 2015, 8, 14 .

7. Bigongiari, M. The Digital Documentation of the Florentine Complex of Santa Maria Maddalena De' Pazzi. In Putting Tradition into Practice: Heritage, Place and Design; Amoruso, G., Ed.; Springer: Cham, Switzerland, 2017.

8. Pancani, G. La Città dei Guidi: Poppi. Il costruito del centro storico, rilievi e indagini diagnostiche; Edifir: Firenze, Italy, 2017; pp. 133-137.

9. Parrinello, S.; Picchio, F.; Bercigli, M. The 'migration' of reality in virtual scenarios: Databases and documentation systems for the musealization of complex environments. Disegnare Con 2017, 9, 17.

10. Gabbrielli, F. Romanico aretino. L'architettura protoromanica e romanica religiosa nella diocesi medievale di Arezzo; Salimbeni: Firenze, Italy, 1990.

11. Francovich, R.; Felici, C.; Gabrielli, F. La Toscana. In Proceedings of the Le chiese rurali tra V e VI secolo in Italia settentrionale e nelle regioni limitrofe, $9^{\circ}$ seminario sul tardo antico e l'alto medioevo, Garlate, Italy, 26-28 September 2002.

12. Arrighetti, A. Archeologia dell'Architettura e ricognizione di superficie nel comune di Sesto Fiorentino (FI). In Archeologia dell'Architettura; Firenze, Italy, 2012; Volume XVII, pp. 173-190.

13. Boato, A. L'archeologia in architettura. Misurazioni, stratigrafie, datazioni, restauro; Marsilio: Padova, Italy, 2008.

14. Brogiolo, G.P.; Cagnana, A. Archeologia dell'architettura. Metodi ed interpretazioni; All'Insegna del Giglio: Firenze, Italy, 2012.

15. Maetzke, G. Scavi e scoperte nel campo dell'archeologia cristiana negli ultimi dieci anni in Toscana ed in Sardegna. In Atti del II Congresso Nazionale di Archeologia Cristiana; L’Erma di Bretschneider: Roma, Italy, 1969; pp. 320-321.

16. Del Vita, S. La Pieve di S. Pietro a Gropina; Tipografia Commerciale: Montevarchi, Italy, 1988.

(C) 2019 by the authors. Licensee MDPI, Basel, Switzerland. This article is an open access article distributed under the terms and conditions of the Creative Commons Attribution (CC BY) license (http:/ / creativecommons.org/licenses/by/4.0/). 